\title{
Reconstructing Fire Records from Ground-Based Routine Aerosol Monitoring
}

\author{
Hongmei Zhao ${ }^{1}$, Daniel Q. Tong ${ }^{2,3, *}$, Pius Lee ${ }^{2}$, Hyuncheol Kim ${ }^{2,3}$ and Hang Lei ${ }^{2}$ \\ 1 Key Laboratory of Wetland Ecology and Environment, Northeast Institute of Geography and Agroecology, \\ Chinese Academy of Sciences, Changchun 130102, China; zhaohongmei@iga.ac.cn \\ 2 U.S. NOAA Air Resources Laboratory, College Park, MD 20740, USA; pius.lee@noaa.gov (P.L.); \\ Hyuncheol.kim@noaa.gov (H.K.); hang.lei@noaa.gov (H.L.) \\ 3 UMD/Cooperative Institute for Climate and Satellites, College Park, MD 20740, USA \\ * Correspondence: daniel.tong@noaa.gov; Tel.: +1-301-683-1394; Fax: +1-301-683-1370
}

Academic Editor: Rebecca Sheesley

Received: 30 October 2015; Accepted: 10 March 2016; Published: 14 March 2016

\begin{abstract}
Long-term fire records are important to understanding the trend of biomass burning and its interactions with air quality and climate at regional and global scales. Traditionally, such data have been compiled from ground surveys or satellite remote sensing. To obtain aerosol information during a fire event to use in analyzing air quality, we propose a new method of developing a long-term fire record for the contiguous United States using an unconventional data source: ground-based aerosol monitoring. Assisted by satellite fire detection, the mass concentration, size distribution, and chemical composition data of surface aerosols collected from the Interagency Monitoring of Protected Visual Environments (IMPROVE) network are examined to identify distinct aerosol characteristics during satellite-detected fire and non-fire periods. During a fire episode, elevated aerosol concentrations and heavy smoke are usually recorded by ground monitors and satellite sensors. Based on the unique physical and chemical characteristics of fire-dominated aerosols reported in the literature, we analyzed the surface aerosol observations from the IMPROVE network during satellite-detected fire events to establish a set of indicators to identify fire events from routine aerosol monitoring data. Five fire identification criteria were chosen: (1) high concentrations of $\mathrm{PM}_{2.5}$ and $\mathrm{PM}_{10}$ (particles smaller than 2.5 and 10 in diameters, respectively); (2) a high $\mathrm{PM}_{2.5} / \mathrm{PM}_{10}$ ratio; (3) high organic carbon $\left(\mathrm{OC} / \mathrm{PM}_{2.5}\right)$ and elemental carbon $\left(\mathrm{EC} / \mathrm{PM}_{2.5}\right)$ ratios; (4) a high potassium $\left(\mathrm{K} / \mathrm{PM}_{2.5}\right)$ ratio; and (5) a low soil/ $/ \mathrm{PM}_{2.5}$ ratio. Using these criteria, we are able to identify a number of fire episodes close to 15 IMPROVE monitors from 2001 to 2011. Most of these monitors are located in the Western and Central United States. In any given year within the study period fire events often occurred between April and September, especially in the two months of April and September. This ground-based fire climatology is also consistent with that derived from satellite retrievals. This study demonstrates that it is feasible to reconstruct historic records of fire events based on continuous ground aerosol monitoring. This dataset can provide not only fire activity information but also fire-induced aerosol surface concentrations and chemical composition that can be used to verify satellite-based products and evaluate air quality and climate modeling results. However, caution needs to be exercised because these indicators are based on a limited number of fire events, and the proposed methodology should be further tested and confirmed in future research.
\end{abstract}

Keywords: fire; aerosol; ground-based aerosol monitoring; fire identification

\section{Introduction}

Biomass burning, including both wildfires and prescribed burns, converts a sizeable amount of vegetation into burned ashes, fugitive gases, vapor, and particles [1]. The emitted gases, water 
vapor, and fine particles exert myriad effects on atmospheric chemistry, the Earth's radiative budget, and the hydrological cycle [2-4]. Due to the significant effects of wildfire on air quality and climate, wildfire biomass burning events have been extensively studied through ground observations $[5,6]$, satellite sensor detection [5,7-9], and model simulations [10,11]. The continuous accumulation of fire-related data makes it possible for the scientific community to examine long-term trends in fire activity and the driving forces underlying these variations. Using satellite data and a biogeochemical model, van der Werf and colleagues [12] have examined the interannual variability in global biomass burning emissions, which exhibited large variations (with a range of more than $1 \mathrm{Pg} \mathrm{C} \cdot$ year $^{-1}$ ) from 1997 to 2004. Westerling et al. [13] have compiled an extensive wildfire database and found that large wildfire activity in the Western United States (U.S.) has increased considerably since the mid-1980s, likely driven by increased spring/summer temperatures and an earlier snowmelt in the mid-elevation forests of the Northern Rockies. Development of long-term fire climatology, while holding great promise for climate analysis, presents substantial challenges due to the difficulty of obtaining accurate fire observations and the diverse requirements of fire indices. Polar-orbiting satellite sensors, such as the Moderate Resolution Imaging Spectroradiometer (MODIS) [5,8], the Along Track Scanning Radiometer (ATSR) [10], and the Visible and Infrared Scanner (VIIRS) [12], can provide global coverage of fire counts, burned areas, and fire's radiative power. High temporal resolution fire detection could be derived from National Oceanic and Atmospheric Administration (NOAA) Geostationary Operational Environmental Satellite (GOES)-based observations [9]. For both polar-orbiting and stationary satellites, wildfires can be difficult to observe due to cloud cover or fire induced convection. Furthermore, to quantify fire-related emissions, several important assumptions have to be made to convert satellite fire observations into fire emissions data, such as fuel loading, burn duration, emission factors, and plume vertical structure. However, the conversion process is not straightforward or intuitive. For instance, van der Werf et al. [12] reported that burned areas and total fire emissions are largely decoupled because forested areas dominate fire emissions, whereas savanna burning contribute disproportionally to burned area statistics globally. Uncertainty in these procedures hinders emission estimations and needs to be investigated with independent data sources, such as ground and aircraft observations. Ground surveys of fire counts and burned areas have been compiled (e.g., m [13]), but these datasets cannot be directly used to derive fire emissions without further processing. Finally, air quality research and regulatory communities are interested in surface concentrations of pollutants elevated by wildfires. However, there is no direct satellite observation of fire-induced $\mathrm{PM}_{2.5}$ (particles smaller than 2.5 in diameters) surface concentrations and chemical composition. Lately, efforts have been made to convert column aerosol loading into surface concentrations [14]. A previous study focused on surface concentrations without chemical compositions, and sources of $\mathrm{PM}_{2.5}$ were not considered. Clearly, there is need to develop ground-based fire observations.

This study proposes a new method of developing long-term wildfire records from traditional ground aerosol monitoring networks. This dataset, if successfully built, can provide not only fire activity information but also fire-induced aerosol surface concentrations and chemical composition data that can be used to verify satellite-based products, evaluate fire models (e.g., model fire occurrence and characteristics), evaluate biomass burning aerosol properties simulated by chemical transport, evaluate general circulation aerosol models using satellite-derived fire emissions, evaluate air quality and climate modeling results, and assess human exposure to fire pollution. The aerosol data are obtained from the Interagency Monitoring of Protected Visual Environments (IMPROVE) network. IMPROVE is a long-term, continuous aerosol monitoring network that measures the mass concentrations, size distribution, and chemical composition of ambient aerosols, and it provides 24-hour aerosol data every third day.

The main challenge of the new method lies in how to design effective criteria to identify fire events from mixed aerosol records. Routine aerosol networks such as IMPROVE were not designed exclusively for fire detection. Instead, IMPROVE observes aerosol levels originating from all sources, such as fires, dust storms, and anthropogenic sources. We use concurrent satellite fire detection and 
IMPROVE data to examine the distinct physical and chemical characteristics of aerosols during fire episodes, so that a set of indicators can be established to separate fire-influenced samples from those dominated by other sources.

\section{Data Sources}

\subsection{IMPROVE Aerosol Data}

There are two reasons for choosing aerosol observation data from the IMPROVE network. First, the IMPROVE network is one of two national air quality monitoring networks in the U.S. It has been providing both mass concentrations and chemical compositions of aerosols every three days since 1988, which makes it ideal for long-term studies. Second, the IMPROVE monitors are mostly deployed in the national parks and remote areas in the U.S. [15], making it suitable for fire detection due to their distance from possible anthropogenic contamination. Locations of IMPROVE monitors over the contiguous United States (CONUS) are shown in Figure 1. There are other monitoring networks, such as the U.S. EPA Air Quality System (AQS) network, which has a national coverage but no aerosol composition data, and the Chemical Speciation Network (CSN), mostly deployed in urban areas and thus possibly affected by anthropogenic contamination. Hence, the IMPROVE network is selected for developing a ground-based fire detection method over the CONUS.

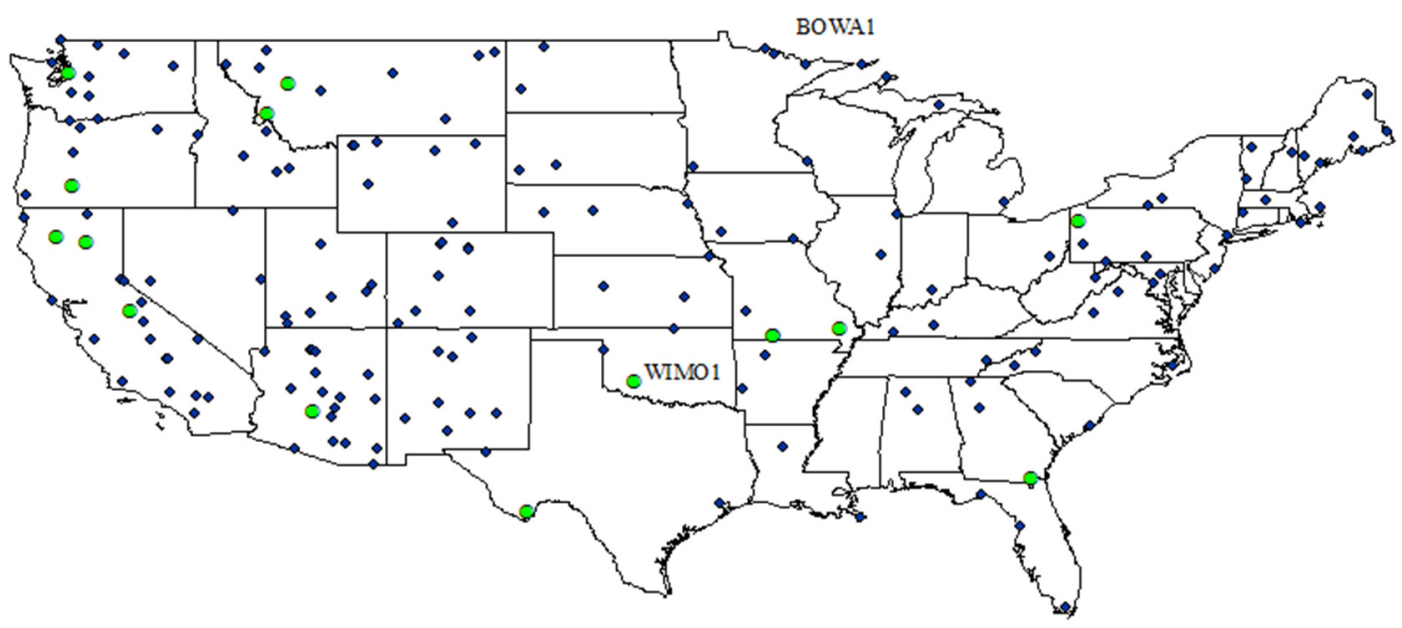

Figure 1. Locations of IMPROVE monitors (marked as $\bullet$ ) over the contiguous United States. The 15 sites (marked as ${ }^{\circ}$ ) indicate the locations where most fire events have been identified from 2001 to 2011 using the approach developed in this work.

\subsection{Satellite Data}

To train the fire detection algorithm, independent fire information is required. A typical source of fire data is satellite remote sensing. Fire events independently recorded by the U.S. National Aeronautics and Space Administration (NASA) Earth Observatory's Natural Hazards Products and other MODIS fire products are used here to assist with the ground-based analysis. These products provide fire information, including start time, end time, duration, burned scar area, and plume direction during fire events. These data are important for establishing fire identification criteria through analysis of the chemical and physical characteristics of fire events using concurrent ground observations. Therefore, we selected some satellite-detected fire events and examined the corresponding IMPROVE data collected around those fires to analyze the characteristics of the filter-based aerosol sample. 


\section{Identifying Fire Events}

\subsection{Selecting Fire Identification Criteria}

Fire identification criteria were proposed based on the chemical and physical characteristics of biomass burning-dominated aerosol data reported in the literature. Prior studies have provided a collective view of particle mass emission factors [5,16-18], size distributions [19], and optical and physical properties of biomass burning emissions [2,3]. These studies formed the basis for particle mass and concentration characterization in accordance with: $\mathrm{PM}_{2.5}$ and $\mathrm{PM}_{10}$ (particles smaller than $10 \mu \mathrm{m}$ in diameter) mass concentrations, ratio of $\mathrm{PM}_{2.5}$ to $\mathrm{PM}_{10}$, percentages of Organic Carbon (OC), Elemental Carbon (EC), potassium (K), and soil in $\mathrm{PM}_{2.5}$. During a fire episode, heavy smoke and low visibility are common, due to the large amount of fine and coarse particles emitted into the ambient air. Therefore, Particulate Matter (PM) concentration in the source region register elevated spikes when a fire event occurs. However, these spikes are not unique to fire events. Had there been a dust event or a volcanic plume, there would have been equal or higher PM concentration spikes. Therefore, to reliably attribute PM concentration spikes to a fire event rather than to a dust event, other indicators must be considered. A previous study documented that approximately $95 \%$ of the particles emitted from biomass burning are fine particles, and the dominant chemical components are carbonaceous [20]. Some reports also suggest that carbon accounts for $50 \%$ to $70 \%$ of the total mass of fire-emitted aerosols, with $55 \%$ and $8 \%$ of the fine particle mass attributed to OC and EC, respectively [3]. Therefore, a high $\mathrm{PM}_{2.5} / \mathrm{PM}_{10}$ ratio, dominated by high $\mathrm{OC} / \mathrm{PM}_{2.5}$ and $\mathrm{EC} / \mathrm{PM}_{2.5}$ ratios, are additional aerosol characteristics pertinent to a fire event. Furthermore, trace inorganic species account for approximately $10 \%$ of the fine mass of fresh smoke, mostly enriched in $\mathrm{K}[3,21]$. Consequently, a high $\mathrm{K} / \mathrm{PM}_{2.5}$ ratio can also be considered as a fire event indicator.

\subsection{Determining Threshold Values for Fire Identification Criteria}

Next, we focus on a number of satellite-detected fire events to determine proper thresholds for each fire identification criterion. We checked the locations and times of some large fire events detected by satellites. We examined satellite imageries for fire events from the NASA Earth Observatory's Natural Hazards fire products [22], and MODIS fire maps [23]. We then merged these fire maps with the corresponding geographic coverage from IMPROVE network sites using the geo-spatial software in ArcGIS.

First, we focused on the BOWA1 site (marked in Figure 1) with a case study. A lightning strike in the Boundary Waters Canoe Area Wilderness Region of northeastern Minnesota started a forest fire. On 12 September 2011, fire event imageries were captured by MODIS aboard the Terra satellite (Figure 2). The fire was a plume-driven event, and it ultimately burned more than 60,000 acres. According to the IMPROVE aerosol data, during the fire event between September 9th and 18th (no data on 6th and 12th September 2011), the average concentrations of $\mathrm{PM}_{2.5}, \mathrm{PM}_{10}$, OC, and EC were $14.89,18.31,7.49$, and $0.62 \mu \mathrm{g} \cdot \mathrm{m}^{-3}$, respectively. By contrast, during average background conditions, these values were $4.39,6.38,1.77$, and $0.13 \mu \mathrm{g} \cdot \mathrm{m}^{-3}$, respectively. Although there were no data during part of this fire episode, these results suggest that there was a fire event detected by the IMPROVE monitor. 

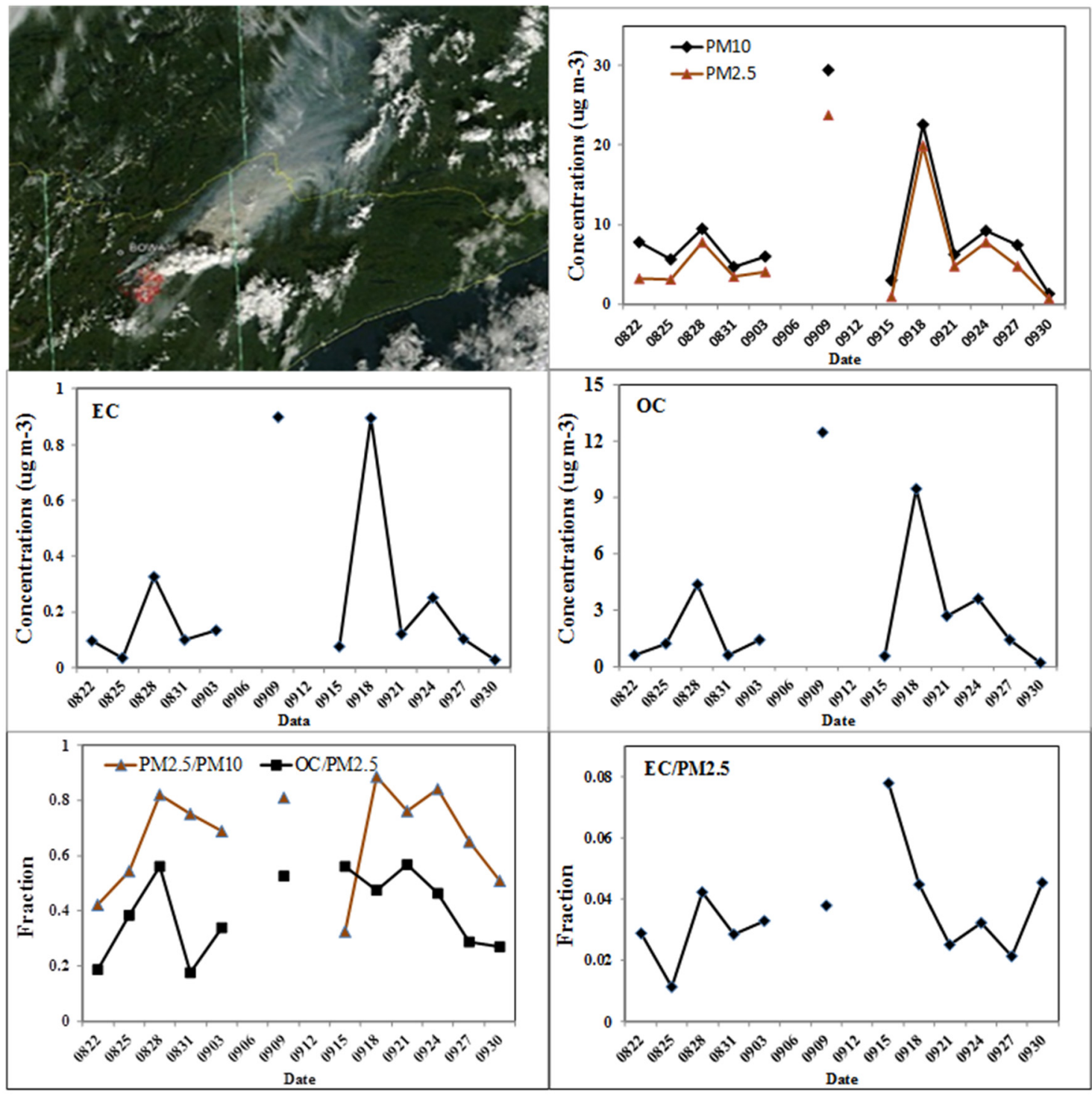

Figure 2. A case study of a fire event in September 2011 at the BOWA1 site. The MODIS on NASA's Terra satellite captured the top left image on 12th September 2011. Red outlines show areas of high surface temperatures associated with active burning, near the BOWA1 site. Characteristics of fire-dominated aerosol $\left(\mathrm{PM}_{2.5}, \mathrm{PM}_{10}, \mathrm{OC}\right.$, and $\mathrm{EC}$ concentrations, ratios of $\mathrm{EC}, \mathrm{OC}$ in $\left.\mathrm{PM}_{2.5}\right)$ during the fire event episode are shown in other figures.

We analyzed aerosol observation data from the IMPROVE sites during the satellite-detected fire episodes. We analyzed the temporal variability of these indicators (concentrations of $\mathrm{PM}_{10}$ and $\mathrm{PM}_{2.5}$ and the ratios of $\mathrm{PM}_{2.5} / \mathrm{PM}_{10}, \mathrm{OC} / \mathrm{PM}_{2.5}, \mathrm{EC} / \mathrm{PM}_{2.5}, \mathrm{~K} / \mathrm{PM}_{2.5}$, and soil/ $/ \mathrm{PM}_{2.5}$ ) before, during, and after the fire episode for a span of 15 days. Compared with the no-fire period conditions, the concentrations of $\mathrm{PM}_{10}$ and $\mathrm{PM}_{2.5}$ and the ratios of $\mathrm{PM}_{2.5} / \mathrm{PM}_{10}, \mathrm{OC} / \mathrm{PM}_{2.5}, \mathrm{EC} / \mathrm{PM}_{2.5}$, and $\mathrm{K} / \mathrm{PM}_{2.5}$ were higher, and the ratio of soil/ $\mathrm{PM}_{2.5}$ was lower (Figure 3) during fire conditions. Finally, we determined the thresholds of fire identification criteria (Table 1) by summarizing aerosol characteristics from both prior studies and measurements from the IMPROVE sites. 

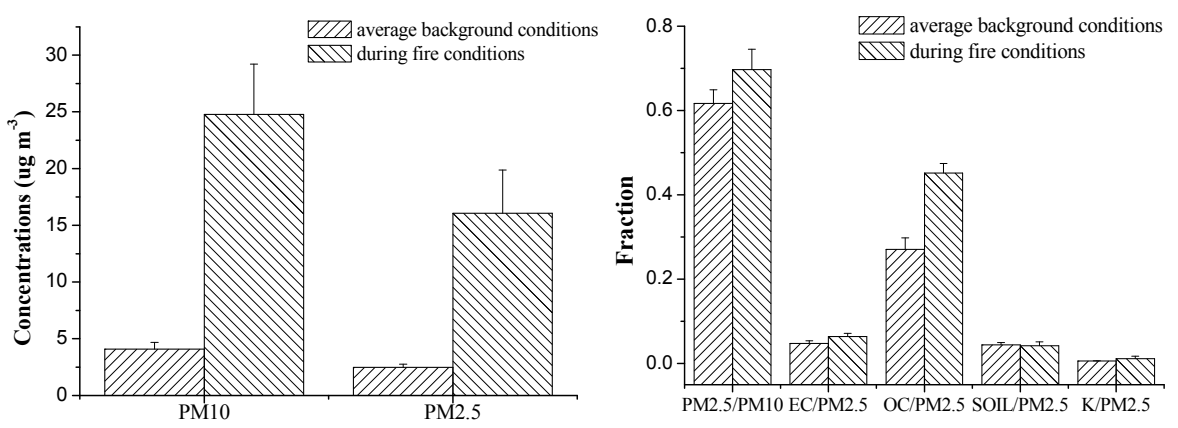

Figure 3. Comparison of fire identification criteria values during fire conditions and average background concentrations or conditions sampled by the monitoring site.

Table 1. Thresholds of fire identification criteria used in this study.

\begin{tabular}{cccccccc}
\hline Indicator & $\mathbf{P M}_{2.5}\left(\mu \mathrm{g} / \mathrm{m}^{3}\right)$ & $\mathbf{P M}_{10}\left(\mu \mathrm{g} / \mathrm{m}^{3}\right)$ & $\mathbf{P M}_{2.5} / \mathbf{P M}_{\mathbf{1 0}}$ & $\mathbf{O C} / \mathbf{P M}_{2.5}$ & $\mathbf{E C} / \mathbf{P M}_{2.5}$ & $\mathbf{K} / \mathbf{P M}_{2.5}$ & Soil/ $_{\mathbf{P M}} \mathbf{P M}_{2.5}$ \\
\hline Static threshold & $>15$ & $>18$ & $>0.6$ & $>0.35$ & $>0.05$ & $>0.003$ & $<0.03$ \\
\hline
\end{tabular}

\subsection{Applying the Approach to Identify Fire Events}

Finally, we applied the fire identification criteria and the corresponding thresholds to all IMPROVE sites to identify fire events between 2001 and 2011. A large number of fire events were identified at 15 IMPROVE sites (marked in Figure 1). Most of these events were located in the Western U.S., particularly in the states of California and Montana, and the Central U.S., especially in the states of Missouri, Oklahoma, and Texas. A previous study based on the GOES burned area product also documented that fires occurred most frequently in the Western and Southeastern U.S., and along the Central and Southern Mississippi Valley [9]. In the Western U.S., due to the dry climate and dense forests (or shrubs), the increased threat of larger, longer, and more intensive forest fires has become a concern $[13,24]$. A previous study documented that California, dominated by shrubland, was a high-intensity fire event area, with fires extending to sizes of 10,000 ha or more [25]. The surface-monitor-based methodology shows that fire has a great impact on local air quality. Unlike satellite-retrievals, our method can provide information about aerosol concentrations and chemical composition attributed to these fire events. The changes in $\mathrm{PM}_{2.5}$ levels and composition caused by fire emissions vary over time and space [24]. For example, the concentrations of $\mathrm{PM}_{2.5}$ were higher in the Eastern U.S. and lower in the central regions, with strong seasonal patterns [26]. In the Western U.S., the annual average percentage of OC in $\mathrm{PM}_{2.5}$ is $40 \%$, whereas in the eastern U.S. it is $25 \%$, with an annual average of $28 \%$ for the whole U.S. For the entire year, the average in summer is higher than that in winter for the U.S., both regionally and CONUS-wide [26]. Therefore, the indicators should be specific for region and season.

Due to the differences in PM concentration and composition over time and space, regional and seasonal characteristics should be considered when applying fire indicators. Here we analyzed the temporal pattern of PM and the ratios of some species in $\mathrm{PM}_{2.5}$ at the WIMO1 site (Figure 4). The results showed that $\mathrm{PM}_{2.5}, \mathrm{PM}_{10}$ concentrations, and the $\mathrm{PM}_{2.5} / \mathrm{PM}_{10}$ ratio were seasonally distinctive: higher in summer and lower in winter, with annual means of $7.3 \mu \mathrm{g} \cdot \mathrm{m}^{-3}, 14.9 \mu \mathrm{g} \cdot \mathrm{m}^{-3}$, and $0.5 \mu \mathrm{g} \cdot \mathrm{m}^{-3}$, respectively. However, the $\mathrm{EC} / \mathrm{PM}_{2.5}$ ratio was higher in fall and lower in summer during the study period. Compared to the annual mean values, the data during the identified fire episodes were higher. This result suggested that the identification criteria worked well. Furthermore, we analyzed the monthly mean values of all indicators at the WIMO1 site (Figure 5). The results showed that OC/PM 2.5 and $\mathrm{EC} / \mathrm{PM}_{2.5}$ ratios are higher in March and October, but lower in July. Especially in July, the lower mean values of $\mathrm{OC} / \mathrm{PM}_{2.5}$ and $\mathrm{EC} / \mathrm{PM}_{2.5}$ ratios indicated that some fire events may have been missed. This result suggested that applying month-specific indicator values could enhance the method to generate more consistent reporting. 

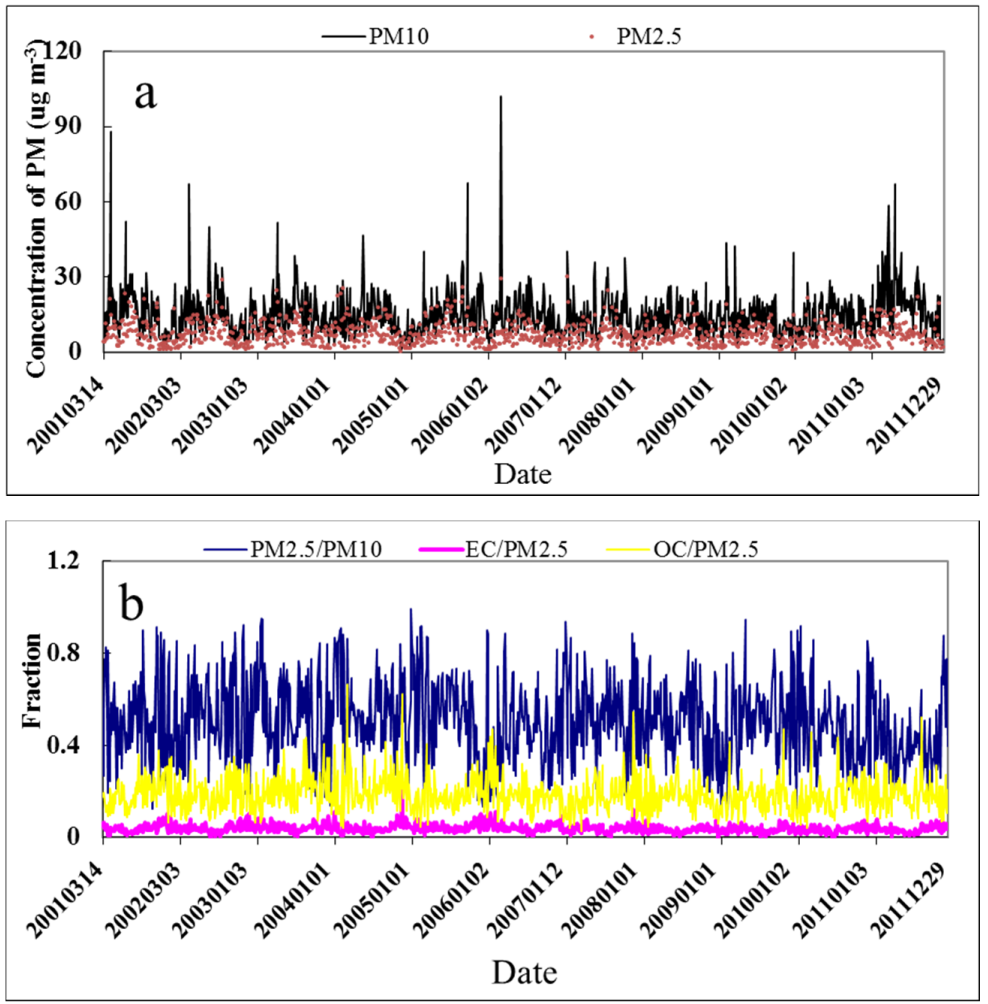

Figure 4. Characteristics of aerosols (a) Concentrations of $\mathrm{PM}_{2.5}$ and $\mathrm{PM}_{10}$; (b) Fractions of $\mathrm{PM}_{2.5} / \mathrm{PM}_{10}$, $\mathrm{EC} / \mathrm{PM}_{2.5}, \mathrm{OC} / \mathrm{PM}_{2.5}$ ) at the WIMO1 site from 2001 to 2011.

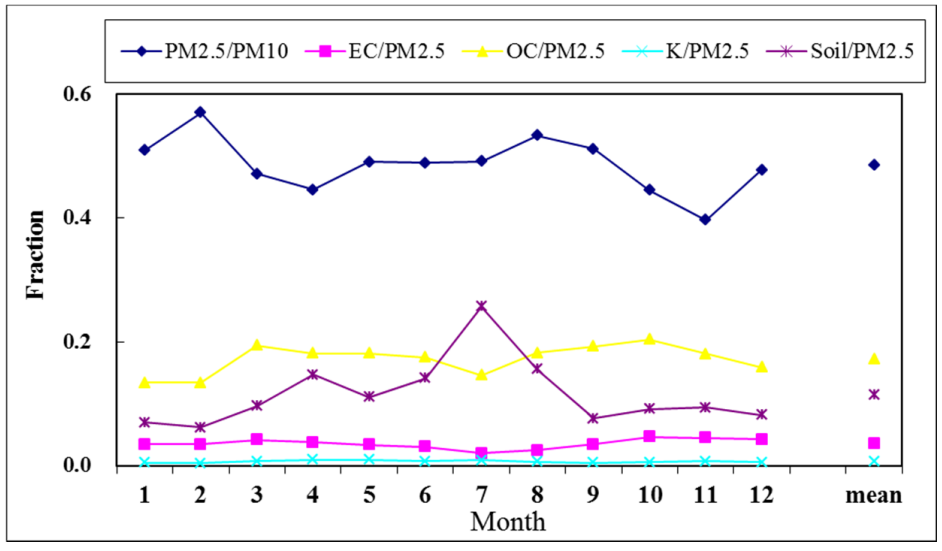

Figure 5. The monthly average of fire indicators at the WIMO1 site.

\subsection{Testing Fire Identification Criteria}

Finally, we analyzed the temporal and spatial characteristics of fire events to test this methodology. Following the suggested procedures, we were able to identify fire events in the proximity of 15 IMPROVE monitoring sites from 2001 to 2011. We compared those identified fire events with the HYbrid Single-Particle Lagrangian Integrated Trajectory (HYSPLIT) back-trajectory model $[27,28]$ prediction, wildland fire summary and statistics annual report by the National Interagency Fire Center [29], and USGS's (United States Geological Survey) record of fire events [30] to confirm these events. We looked at trajectories from the locations of fires identified in satellite imageries and compared fire reports with these results. Most of fires identified by this method were consistent with the records. In fact, there were some fire events detected by this method but missed by satellite due to cloud cover. Furthermore, some fire events were missed by the annual report due to the small size 
of the burned areas, and only fires over 40,000 acres were marked in the wildland fire summary and statistics annual report. For example, we identified a fire event at the WIMO1 site on 30 May 2011, according to fire identification criteria. Then, we compared this result with the HYSPLIT simulation on the same day (provided by the NOAA ARL READY online platform). Fire points, light smoke, medium smoke, and heavy smoke can be found in the HYSPLIT simulation picture. From the picture, we found that there were fire events in Texas and the Gulf of Mexico USA, but no fire located near the WIMO1 site. Heavy smoke from Texas and the Gulf of Mexico may have caused this fire event to be missed by satellite. In addition, we analyzed the temporal and spatial characteristics of aerosols in identified fire events, and found that most of them were located in the Western U.S. (including California and Montana) and the Central U.S. (including Missouri, Oklahoma and Texas).

We chose the WIMO1 site $\left(34.7315^{\circ} \mathrm{N}, 98.7155^{\circ} \mathrm{W}\right)$ in the case study for two reasons: (1) Frequent fires were detected at this site both by satellite and by this method; (2) this site is located in the Wichita Mountains in Oklahoma State, and Oklahoma and Texas are the two states with the most fire events recorded (Figure 1). Here, we calculated days of fire and numbers of fire events from 2001 to 2011. Because a fire can last for several days, if some fire events were identified by indicators for several consecutive days, we considered this one event. There were 83 fire events (161 days) identified between 2001 and 2011 at the WIMO1 site. We analyzed the characteristics of fire-dominated aerosol at the WIMO1 site between 2001 and 2011 (Figure 6). The results showed that concentrations of $\mathrm{PM}_{2.5}$ and $\mathrm{PM}_{10}$ were 14.2 and $21.2 \mu \mathrm{g} \cdot \mathrm{m}^{-3}$ during fire events, respectively. Compared with background conditions, these values were elevated by $42.7 \%$ and $94.6 \%$, respectively. The mean fraction of $\mathrm{PM}_{2.5}$ in $\mathrm{PM}_{10}$ was $66.4 \%$ during fire events, whereas the value was $50.0 \%$ during average background conditions, which also increased by $32.8 \%$. Compared with the variations in PM concentrations, the fractions of some species in the aerosol were more stable. Because aerosol concentrations in smoke plumes were affected by fire intensity, severity, duration, fuel loading, wind direction, and site location, the ratios of species in aerosol were strongly dependent on the sources of aerosols (fire, dust or other natural and anthropogenic sources).
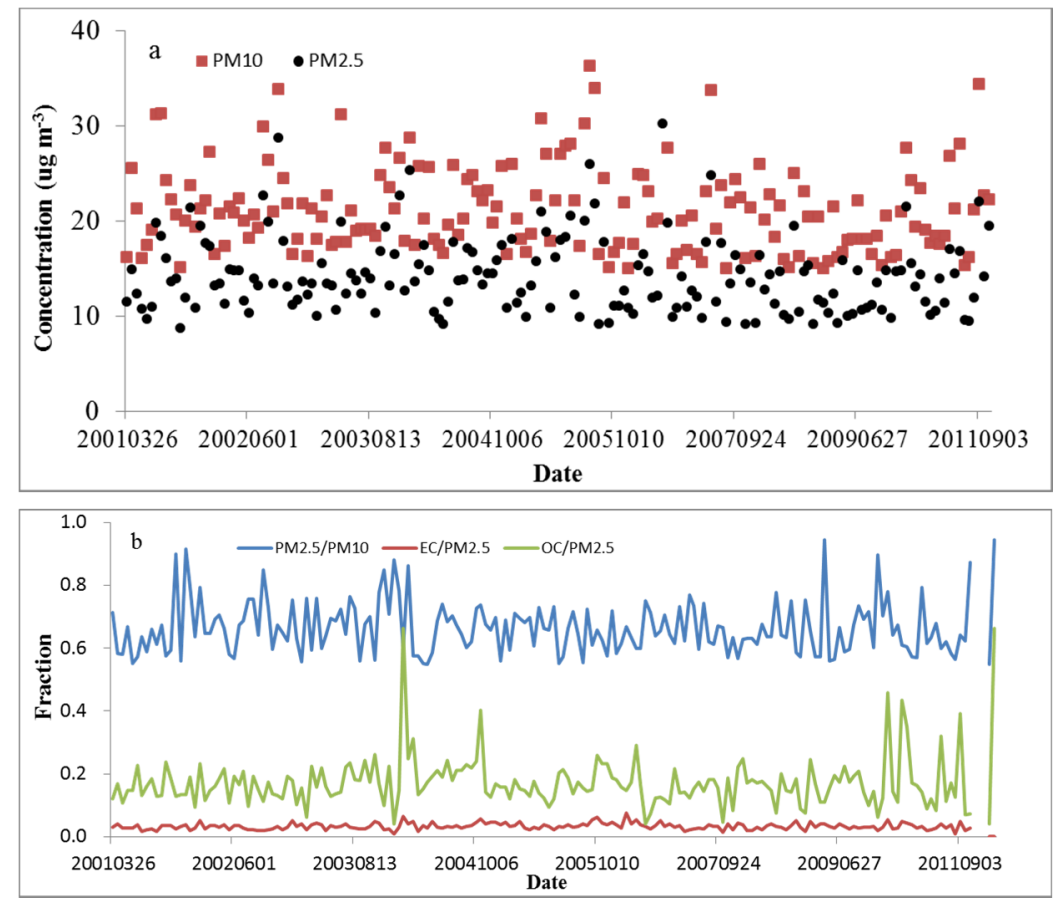

Figure 6. Characteristics of aerosols. (a) Concentrations of $\mathrm{PM}_{2.5}$ and $\mathrm{PM}_{10}$; (b) Fractions of $\mathrm{PM}_{2.5} / \mathrm{PM}_{10}, \mathrm{EC} / \mathrm{PM}_{2.5}, \mathrm{OC} / \mathrm{PM}_{2.5}$ ) during fire events at the WIMO1 site between 2001 and 2011. 
Temporal patterns of fires at the WIMO1 site were distinctive. Between 2001 and 2011, the number of days with fires declined at the WIMO1 site (Figure 7). From 2001 to 2005, there were more than 16 days with fire records every year, including up to 26 days in 2005. However, from 2006 to 2011, the number of fire days declined, and there were fewer than 10 days in 2006. In any given year within the study period, fire events often occurred between April and September, especially in the two months of September and April (Figure 8). The spatial and temporal patterns of fires were often affected by topography, vegetation, climate, and human activity [31]. Previous studies of burned areas, which used data from the AVHRR (the Advanced Very High Resolution Radiometer) and GOES satellite, also documented that fire exhibits a distinctive seasonality, with a peak from June to August. In croplands, peak burning occurred from April to September because agricultural fires were set during pre-planting and post harvesting periods [9,32]. In this study, peak fire events in September may be related to agricultural burnings.

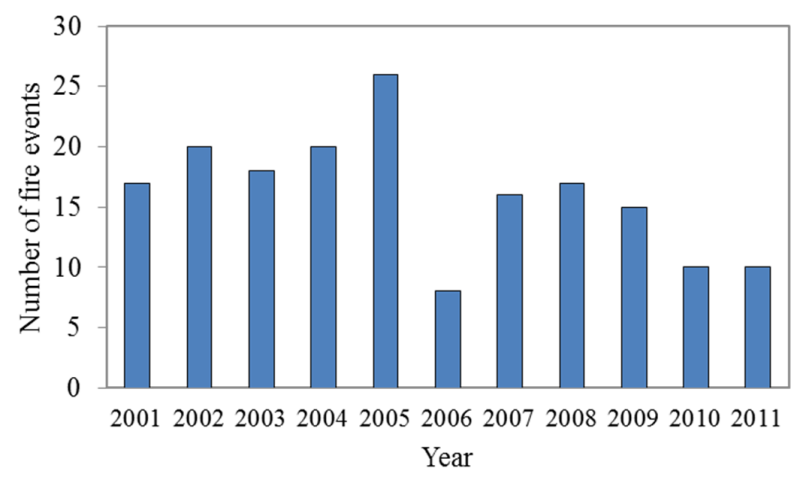

Figure 7. Number of fire events in every year from 2001 to 2011 at the WIMO1 site.

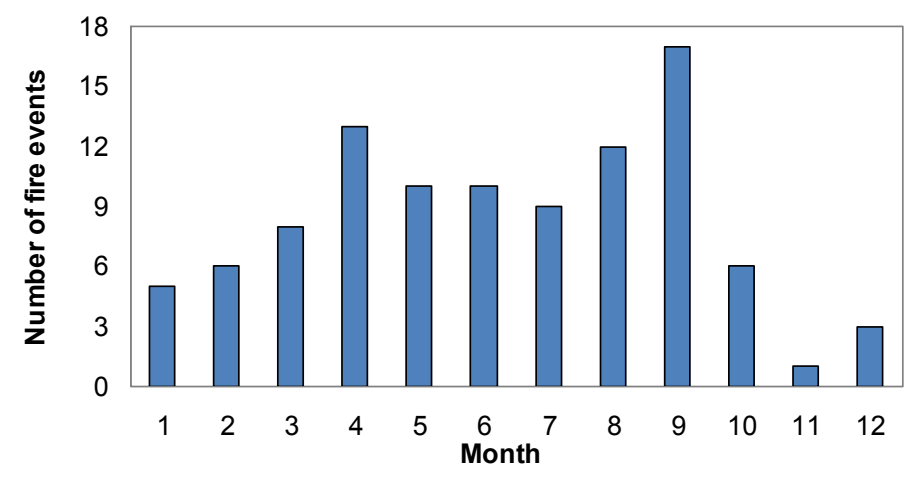

Figure 8. Number of fire events in every month between 2001 and 2011 at the WIMO1 site.

\section{Discussion of Uncertainties and Limitations}

The above results confirm that the proposed methodology has the potential to identify a fire event and quantify its impact on air quality. However, caution needs to be exercised because the indicators discussed here are based on a limited number of fire events. We should take note of the uncertainties and limitations of the methodology, which are caused by the following factors: (1) the sampling frequency (every third day) and the rather sparse distribution of the IMPROVE sites limit the capability of the IMPROVE network to detect all fires, especially for regions with high fire frequency but few IMPROVE sites; (2) neighboring monitoring sites may detect the same fires, resulting in double-counting; (3) excessive loading of smoke ash and other aerosols may disable the instruments; and finally (4) interference by background aerosols makes it difficult to clearly determine thresholds for the fire identification criteria. Aerosol concentrations and chemical composition are intrinsically highly variable over time and space. Consequently, one uniform threshold may not be applicable to all sites 
at all times. Low thresholds may cause false detection, whereas high thresholds may cause omission of some fire counts. For example, the results of this study showed that there were fewer fire events during winter compared with other seasons. This result can be explained by winter's vegetation and climate conditions, which are unfavorable for fires. Another reason may be that the concentrations of PM in winter are near the annual minimum. They cannot reach the threshold concentration level to trigger a fire count by the identification algorithm. If we use the average concentrations of the entire year as a cutoff value, the winter data will be omitted, and few fires will be identified. However, especially in the southern U.S., such as in Florida, fire events also occur in winter, but cannot be identified by this method due to low seasonal aerosol concentrations. Therefore, thresholds for these indicators should be adjusted according to region and season instead of adopting one uniform value.

\section{Summary}

Fire is a major source of aerosol. However, few observation sites are designed to record fire events and to track aerosol emissions from biomass burning. This work proposed a new approach to the reconstruction of historic fire records based on observations collected by a continuous ground-based aerosol monitoring network over the contiguous United States. Using five fire identification criteria, we were able to identify a number of fire episodes recorded by 15 IMPROVE monitors from 2001 to 2011. Most of these fire events were located in the Western and Central United States. In any given year within the study period, fire events often occurred between April and September, especially in the two months of April and September. There were 83 fire events (161 days) at WIMO1 sites between 2001 and 2011. This study demonstrates that it is feasible to reconstruct historic records of fire events based on continuous ground aerosol monitoring. This dataset would provide not only fire activity information but also fire-induced aerosol surface concentrations and chemical composition data that can be used to verify satellite-based products, evaluate air quality and climate modeling results, and assess human exposure to fire pollution. However, caution needs to be exercised because these indicators are based on a limited number of fire events, and the proposed methodology should be further tested and confirmed by future research.

Acknowledgments: We thank the three anonymous reviewers for their constructive comments and helpful suggestions. This work is financially supported by the National Key Technology R\&D Program (No. 2014BAC16B03), the National Natural Science Foundation of China (No. 41201495), the Chinese Academy of Sciences/State Administration of Foreign Experts Affairs (CAS/SAFEA) International Partnership Program for Creative Research Teams (No. KZZD-EW-TZ-07), and the Natural Science Foundation of Jilin Province (No. 20150101010JC). The assistance of the U.S. NOAA Air Resources Laboratory is also gratefully acknowledged.

Author Contributions: The study was completed with cooperation among all authors: Daniel Q. Tong and Hongmei Zhao conceived and designed the research topic. Hongmei Zhao conducted the research and wrote the manuscript. Pius Lee, Hyuncheol Kim, and Hang Lei collaborated in discussing the results and providing editorial advice.

Conflicts of Interest: The authors declare no conflicts of interest.

\section{References}

1. Crutzen, P.L.; Andteae, M.O. Biomass burning in the tropics: Impact on atmospheric chemistry and biogeochemical cycles. Science 1990, 250, 1669-1678. [CrossRef] [PubMed]

2. Reid, J.S.; Eck, T.F.; Christopher, S.A.; Koppmann, R.; Dubovik, O.; Eleuterio, D.P.; Holben, B.N.; Reid, E.A.; Zhang, J. A review of biomass burning emissions part III: Intensive optical properties of biomass burning particles. Atmos. Chem. Phys. 2005, 5, 827-849. [CrossRef]

3. Reid, J.S.; Koppmann, R.; Eck, T.F.; Eleuterio, D.P. A review of biomass burning emissions part II: Intensive physical properties of biomass burning particles. Atmos. Chem. Phys. 2005, 5, 799-825. [CrossRef]

4. Mielonen, T.; Aaltonen, V.; Lihavainen, H.; Hyvarunen, A.; Arola, A.; Komppula, M.; Kivi, R. Biomass burning aerosols abserved in Northern Finland during the 2010 wildfires in Russia. Atmosphere 2013, 4, 17-34. [CrossRef] 
5. Wiedinmyer, C.; Quayle, B.; Geron, C.; Belote, A.; McKenzie, D.; Zhang, X.; O’Neill, S.; Wynne, K.K. Estimating emissions from fires in North America for air quality modeling. Atmos. Environ. 2006, 40, 3419-3432. [CrossRef]

6. $\quad$ Burling, I.R.; Yokelson, R.J.; Akagi, S.K.; Urbanski, S.P.; Wold, C.E.; Griffith, D.W.T.; Johnson, T.J.; Reardon, J.; Weise, D.R. Airborne and ground-based measurements of the trace gases and particles emitted by prescribed fires in the United States. Atmos. Chem. Phys. 2011, 11, 12197-12216. [CrossRef]

7. Hsu, N.C.; Herman, J.R.; Bhartia, P.K.; Seftor, C.J.; Torres, O.; Thompson, A.M.; Gleason, J.F.; Eck, T.F.; Holben, B.N. Detection of biomass burning from TOMS measurements. Geophys. Res. Lett. 1996, 23, 745-748. [CrossRef]

8. Ichoku, G.; Giglio, L.; Wooster, M.J.; Remer, L.A. Global characterization of biomass-burning patterns using satellite measurements of fire radiative energy. Remote Sens. Environ. 2008, 112, 2950-2962. [CrossRef]

9. Zhang, X.Y.; Kondragunta, S. Temporal and spatial variability in biomass burned area across the USA derived from the GOES fire product. Remote Sens. Environ. 2008, 112, 2886-2897. [CrossRef]

10. Duncan, B.N.; Martin, R.V.; Staudt, A.C.; Yevich, R.; Logan, J.A. Interannual and seasonal variability of biomass burning emissions constrained by satellite observations. J. Geophys. Res. 2003, 108. [CrossRef]

11. Wang, J.; Christopher, S.A.; Nair, U.S.; Reid, J.S.; Prins, E.M.; Szykman, J.; Hand, J. Mesoscale modeling of Central American smoke transport to the United States: 1. "Top-down" assessment of emission strength and diurnal variation impacts. J. Geophys. Res. Atmos. 2006, 111. [CrossRef]

12. Van der Werf, G.R.; Randerson, J.T.; Giglio, L.; Collatz, G.J.; Mu, M.; Kasibhstla, P.S.; Morton, D.C.; DeFries, R.S.; Jin, Y.; van Leeuwen, T.T. Global fire emission and the contribution of deforestation, savanna, forest, agricultural, and peat fires (1997-2009). Atmos. Environ. 2010, 40, 3419-3432.

13. Westerling, A.L.; Hidalgo, H.G.; Cayan, D.R.; Swetnam, T.W. Warming and earlier spring increase western U.S. forest wildfire activity. Science 2006, 313, 940-943. [CrossRef] [PubMed]

14. Boys, B.L.; Martin, R.V.; van Donkelaar, A.; MacDonell, R.J.; Hsu, N.C.; Cooper, M.J.; Yantosca, R.M.; Lu, Z.; Streets, D.G.; Zhang, Q.; et al. Fifteen-year global time series of satellite-derived fine particulate matter. Environ. Sci. Technol. 2014, 48, 11109-11118. [CrossRef] [PubMed]

15. Pitchford, M.L.; Malm, W.C. Development and applications of a standard visual index. Atmos. Environ. 1994, 28, 1049-1054. [CrossRef]

16. Akagi, S.K.; Yokelson, R.J.; Wiedinmyer, C.; Alvarado, M.J.; Reid, J.S.; Karl, T.; Crounse, J.D.; Wennberg, P.O. Emission factors for open and domestic biomass burning for use in atmospheric models. Atmos. Chem. Phys. 2011, 11, 4039-4072. [CrossRef]

17. Yokelson, R.J.; Burling, I.R.; Gilman, J.B.; Warneke, C.; Stockwell, C.E.; de Gouw, J.; Akagi, S.K.; Urbanski, S.P.; Veres, P.; et al. Coupling field and laboratory measurements to estimate the emission factors of identified and unidentified trace gases for prescribed fires. Atmos. Chem. Phys. 2013, 13, 89-116. [CrossRef]

18. Urbanski, S. Wildland fire emissions, carbon, and climate: Emission factors. Forest Ecol. Manag. 2014, 317, 51-60. [CrossRef]

19. Janhall, S.; Andreae, M.O.; Poschl, U. Biomass burning aerosol emissions from vegetation fires: Particle number and mass emission factors and size distributions. Atmos. Chem. Phys. 2010, 10, 1427-1439. [CrossRef]

20. Deng, C.R. Identification of Biomass Burning Source in Aerosols and the Formation Mechanism of Haze. Ph.D. Thesis, University of Fudan, Shanghai, China, 15 April 2011. (in Chinese).

21. Amodio, M.; Andriani, E.; Dambruoso, P.R.; Daresta, B.E.; de Gennaro, G.; di Gilio, A.; Intini, M.; Palmisani, J.; Tutino, M. Impact of biomass burning on $\mathrm{PM}_{10}$ concentrations. Fresen. Environ. Bull. 2012, 21, 3296-3300.

22. The NASA Earth Observatory's Natural Hazards fire products. Available online: http:/ / earthobservatory.nasa.gov / NaturalHazards/category.php?cat_id=8\&m=01\&y=2013 (accessed on 23 July 2013).

23. MODIS fire maps. Available online: http://reverb.echo.nasa.gov/reverb/\#utf8=\%E2\%9C\%93\&spatial_map= satellite\&spatial_type=rectangle\&keywords=MOD14 (accessed on 23 July 2013).

24. Schoennagel, T.; Veblen, T.T.; Romme, W.H. The interaction of fire, fuels, and climate across Rocky Mountain forests. BioScience 2004, 54, 661-676. [CrossRef]

25. Keeley, J.E.; Zedler, P.H. Large, high-intensity fire events in southern California shrublands: Debunking the fine-grain age patch model. Ecol. Appl. 2009, 19, 2254. [CrossRef] 
26. Bell, M.L.; Dominici, F.; Ebisu, K.; Zeger, S.L.; Samet, J.M. Spatial and temporal variation in PM 2.5 chemical composition in the United States for health effects studies. Environ. Health Perspect. 2007, 115, 988-995. [CrossRef] [PubMed]

27. Draxler, R.R.; Rolph, G.D. HYbrid Single-Particle Lagrangian Integrated Trajectory (HYSPLIT) Model access via NOAA ARL READY. Available online: http:/ /www.arl.noaa.gov/HYSPLIT_info.php (accessed on 23 July 2012).

28. Rolph, G.D. Real-time Environmental Applications and Display System (READY). Available online: http:/ / ready.arl.noaa.gov/index.php (accessed on 23 July 2012).

29. The National Interagency Fire Center. Available online: http://www.nifc.gov/fireInfo/fireInfo_statistics. html (accessed on 23 July 2013).

30. The United States Geological Survey record of fire events. Available online: http://wildfire.cr.usgs.gov/ firehistory/data.html (accessed on 23 July 2013).

31. Iniguez, J.M.; Swetnam, T.W.; Baisan, C.H. Spatially and temporally variable fire regime on Rincon Peak, Arizona, USA. Fire Ecol. 2009, 5, 3-21. [CrossRef]

32. Pu, R.; Li, Z.; Gong, P.; Csiszar, I.; Fraser, R.; Hao, W.; Kondragunta, S.; Weng, F. Development and analysis of a 12-year daily 1-km forest fire dataset across North America from NOAA/AVHRR data. Remote Sens. Environ. 2007, 108, 198-208. [CrossRef]

(C) 2016 by the authors; licensee MDPI, Basel, Switzerland. This article is an open access article distributed under the terms and conditions of the Creative Commons by Attribution (CC-BY) license (http:/ / creativecommons.org/licenses/by/4.0/). 